\title{
Durability Index Performance of High Strength Concretes Made Based on Different Standard Portland Cements
}

\author{
Stephen O. Ekolu ${ }^{1}$ and Sheena Murugan ${ }^{2}$ \\ ${ }^{1}$ School of Civil and Environmental Engineering, University of the Witwatersrand, 1 Jan Smuts Ave, Private Bag 3, \\ WITS 2050, Johannesburg, South Africa \\ ${ }^{2}$ Ready-Mix, Lafarge Industries SA (pty) Ltd., 35 Westfield Road, Longmeadow Business Estate Ext. 11,1609, Private Bag X2, \\ Gallo Manor 2052, Johannesburg, South Africa
}

Correspondence should be addressed to Stephen O. Ekolu, stephen.ekolu@wits.ac.za

Received 19 November 2011; Accepted 28 February 2012

Academic Editor: Gai-Fei Peng

Copyright (C) 2012 S. O. Ekolu and S. Murugan. This is an open access article distributed under the Creative Commons Attribution License, which permits unrestricted use, distribution, and reproduction in any medium, provided the original work is properly cited.

\begin{abstract}
A consortium of three durability index test methods consisting of oxygen permeability, sorptivity and chloride conductivity were used to evaluate the potential influence of four (4) common SANS 10197 cements on strength and durability of concrete. Twenty four (24) concrete mixtures of water-cement ratios (w/c's) $=0.4,0.5,0.65$ were cast using the cement types CEM I 42.5N, CEM II/A$\mathrm{M}$ (V-L) 42.5N, CEM IV/B 32.5R and CEM II/A-V 52.5N. The concretes investigated fall in the range of normal strength, medium strength and high strength concretes. It was found that the marked differences in oxygen permeability and sorptivity results observed at normal and medium strengths tended to vanish at high concrete strengths. Also, the durability effects attributed to use of different cement types appear to diminish at high strengths. Cements of low strength and/or that contained no extenders (CEM 32.5R, CEM I $42.5 \mathrm{~N}$ ) showed greater sensitivity to sorptivity, relative to other cement types. Results also show that while concrete resistance to chlorides generally improves with increase in strength, adequately high chloride resistance may not be achieved based on high strength alone, and appropriate incorporation of extenders may be necessary.
\end{abstract}

\section{Introduction}

Increased durability requirements and specifications have been quoted for many infrastructural projects in South Africa recently, especially contracts issued by the South African National Roads Agency. Although there has been a lot of research conducted throughout the world on factors affecting durability and durability test methods, limited research has been done in South Africa using local raw materials and test methods. In the 1990s, South Africa started developing their own test methods based on the key principles of test methods available internationally. Three test methods, one for oxygen permeability, another for water sorptivity, and the third test being chloride conductivity, were developed together with procedures for preparation of the test specimens [1-5]. Since specifying for durability basing on performance is increasingly becoming the trend, it was decided to study the effects of different South African cement types on concrete durability performance.

The deterioration of concrete is dependent upon one or more transport processes, whether the attack is due to chemical mechanisms such as sulphate attack, delayed ettringite formation, alkali silica reaction, and carbonation, or due to physical attack processes such as freeze-thaw damage and thermal cracking. The transport mechanisms by which aggressive agents can ingress into concrete in form of fluids, gas, or liquid are primarily (a) permeability being movement of the media through the pores and cracks of concrete due to pressure differences, (b) diffusion being transportation under concentration gradients, and (c) suction resulting from capillary forces in dry or partially dry materials. The resistance to these transport mechanisms is related to the pore interconnectivity, pore sizes, and the tortuosity of pores and cracks. This leads to the importance of design of 
the concrete mixtures including the kind of material systems used.

\section{High-Strength Concretes and High-Performance Concretes}

High-performance concretes (HPCs) and high-strength concrete (HSC) are distinct and different types of special concretes and yet a particular mix can contain both characteristics giving high strength and high performance at the same time. Indeed in the past, there have been general perceptions that HPC should have high strength and high durability as stated by Addis [3], that HPC is "characterized by its strength and durability." Others have considered HPC to be synonymous with long service life. The different definitions by various authors for HPC and HSC underscores the difficulties in delineating the differences between these two types of concretes. The various definitions can be found summarized in the literature such as $[6,7]$.

2.1. High-Performance Concretes. The American Concrete Institute (ACI) defines HPC [8] as "concrete having desired properties and uniformity that cannot be obtained routinely using only traditional constituents and normal mixing, placing and curing practices." In other words, the definition broadly considers HPC as all Portland cement concretes whose properties are superior or beyond the normal range of conventional concretes. The definition by the Strategic Highway Research Program (SHRP) is quite prescriptive, stating HPC as concrete whose strength is greater than $70 \mathrm{MPa}$, has greater than $80 \%$ durability factor under freeze-thaw, and is made with water-cementitious ratio no greater than 0.35 [9]. But it has been shown that concretes of high strength may show retrogressive performance in durability parameters. For example, concretes of very high early strength are vulnerable to autogenous and thermal shrinkage. In an experimental study by Shah and Weiss, 2000 [10], it was shown that while decreasing the water-cementitious ratio led to improvement in strength, stiffness, and chloride resistance, there was an increase in shrinkage making them more vulnerable to possible early-age thermal cracking. Their study was conducted using concretes of $\mathrm{w} / \mathrm{c}$ 's $=0.3,0.4$, and 0.5 with or without silica fume and shrinkage-reducing admixture. They recommended that specification of highly durable concrete should at the minimum include three parameters of strength, permeability, and early-age cracking. A definition published by the Federal Highway Agency (FHWA) [11] appears to be more plausible, stating HPC as "concrete that has been designed to be more durable and, if necessary, stronger than conventional concrete." In this definition of HPC, durability is advanced as the primary performance criterion, while strength is considered a secondary parameter except where it is the definitive property for required performance.

It is clear that HPC is so regarded, for its superior performance with respect to particular critical characteristics of interest to the application. The typical performance properties may include one or more of the following: high workability, high early or late strength, low permeability, low or high density, low heat of hydration, high resistance to early age cracking, shrinkage and creep, toughness, durability under severe exposure conditions. Mehta and Monterio, 2005 [12], cite high-volume fly ash (HVFA) concrete containing from 50 to $70 \%$ FA concrete, as an example of a concrete mixture that can be considered HPC concrete due to high crack resistance and durability characteristics resulting from highly reduced water content. And yet the compressive strength of HVFA concrete may be low to medium.

It is evident from various literature sources that the use of the term "performance" with regard to durability of concrete has become synonymous with the incorporation of extenders in the concrete mixture with or without high strength. This is related to the effectiveness of extenders in mitigating most, if not all the major physical or chemical processes that often cause degradation in concretes.

2.2. High-Strength Concretes. HSC is so-called purely on the basis of its high-strength development. The enabling technology for HSC came into being when plasticizers and superplasticizers were developed in Japan and Germany in the 1960s, allowing the making of concretes at low water-cement ratios to be possible, a practice which is impossible with conventional concrete. With the use of plasticizing chemical admixtures, both high strength and high workability are achieved at the same time.

The definition of HSC has continuously changed, while there exists disparity in specifications of the strength levels considered to be the threshold limit/s for HSC. HSC was defined by ACI 363 [13] as concrete with a cylinder strength greater than $41 \mathrm{MPa}$. It has recently been speculated that this strength limit may be raised to $55 \mathrm{MPa}$, while ACI 441 [14] puts the strength threshold for HSC at 70/88 MPa. However, it appears to be generally recognized that concretes of compressive strength from 60 to $120 \mathrm{MPa}[15,16]$ are considered HSCs, typically achieved at a low w/c not exceeding 0.35 . The advent of HSC has been driven by the need for high strength and stiffness for the ever growing demand in infrastructure especially in the urban areas being constantly under population growth pressures. Consequently, multistorey structures have become indispensable features needed in the cities. About 30 to 50 years ago, most of the tall skyscrapers were constructed mainly using steel. In the present urban centres, concrete has become the dominant construction material for high-storey structures including some of the tallest buildings in the world today. One example of an important application for high strength is that of precast prestressed concrete. The principles of prestressed concrete (PSC) design show that high-quality, high-strength materials are needed both for steel and concrete. The earlier attempts to produce PSC concrete in the 19th century with low-strength materials failed due to the resulting high prestress losses. When highstrength steel and concrete were used by Freyssinet in about the 1930s, the modern form of PSC was successfully born due to a much reduced prestress loss. This application undercores the typical improvement in material properties of concrete associated with high strength, more especially the improvements in some durability characteristics, creep, and shrinkage [17]. The high stiffness and strength of HSC allows engineers to design members of reduced sectional sizes, 
utilize space more efficiently, and save on the associated construction costs.

The engineering and material properties of HSC are markedly different from those of conventional concrete, hence its treatment as special concrete. It appears that the medium-strength concretes in the range of 40 to $60 \mathrm{MPa}$ are in a transitional range as properties of normal concretes at about $40 \mathrm{MPa}$ progressively change to distinctively different characteristics at high-strength levels. Mcfarlane, 2007 [16], discusses that this transformation may be considered fully achieved at about $80 \mathrm{MPa}$. At the high strengths of concrete, the difference between cylinder and cube strengths diminish and/or vanish completely unlike in normal concrete where cylinder strength is typically $80 \%$ of cube strength. Structurally, concrete becomes brittle with increase in strength, exhibiting a sudden and explosive failure at high strengths. For normal concrete, the stress-strain behaviour is a parabolic or approximately rectangular profile from which the design stress block is derived. At about $100 / 120 \mathrm{MPa}$, HSC exhibits a nearly triangular stress block instead. Accordingly, the design formulae used for conventional structural concrete may not apply to HSC, in which case using the conventional formulae may overestimate the true structural capacity of an HSC member [16].

\section{Experimental}

Four different cement types were selected for the study, namely:

(i) CEM $142.5 \mathrm{~N}$ Portland cement with about 5\% minor additional constituents and a strength enhancer;

(ii) CEM II/A-M (V-L) $42.5 \mathrm{~N}$ Portland composite cement, which incorporates finely ground, high-purity limestone interground with Portland cement clinker, $15 \%$ quality siliceous fly ash, and a strength enhancer;

(iii) CEM IV/B-V 32.5R, which incorporates $40 \%$ fly ash, that is interground with the clinker together with a strength enhancer;

(iv) CEM II/A-V $52.5 \mathrm{~N}$, which is formulated from Portland cement clinker and between 6 to $20 \%$ siliceous fly ash with a strength enhancer.

The aggregates used consisted of $19 \mathrm{~mm}$ dolomite stone and $6.7 \mathrm{~mm}$ dolomite crusher sand. The filler sand used was a decomposed sandstone material. Twenty-four mixes were prepared in total in the laboratory. Mixtures of three different water/cement ratios of $0.4,0.5$, and 0.65 were prepared for each cement type as given in Table 1 . The mixes were designed to yield $20 \mathrm{~L}$ of concrete with the exception of mixes prepared using CEM IV/B-V 32.5R and CEM I 42.5N incorporating filler sand and which were poker vibrated to simulate site compaction. The latter mixes were cast in panels instead of cubes, and hence there were no 28 -day compressive strength results tested for the particular mixes.

Twelve test cubes per mix were made. Concrete cubes were demoulded after 24 hours and immediately stored in curing tanks containing portable water, which was maintained at $23^{\circ} \mathrm{C} \pm 2^{\circ} \mathrm{C}$ until at the time of testing. The cubes

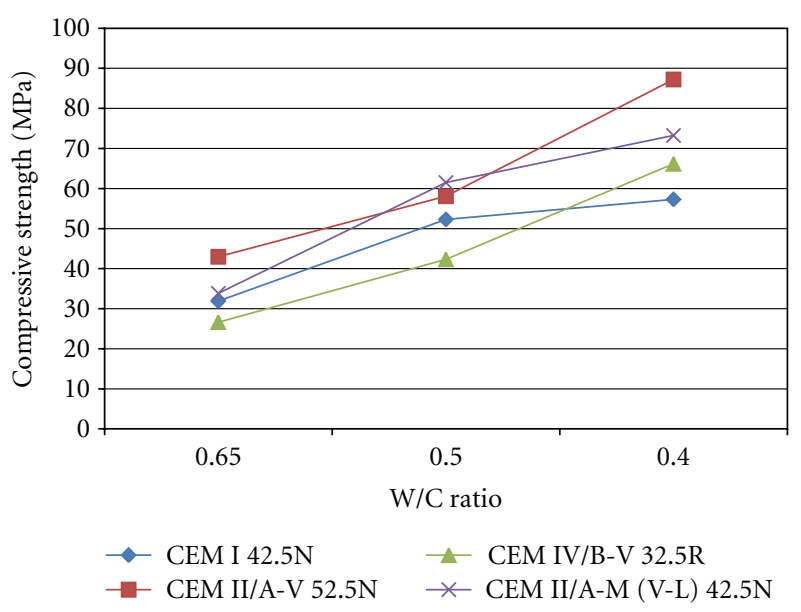

FIGURE 1: 28-day compressive strength for different cement types at different $\mathrm{w} / \mathrm{c}$ ratios.

were then tested for compressive strengths at 28 days. Of the cubes prepared, five test cubes were used to determine compressive strength, five test cubes were used for durability testing, and two test cubes reserved in the curing tank. Three of the five test cubes were used for oxygen permeability index testing and water sorptivity, whilst the remainder two test cubes were used for chloride conductivity testing. Test specimens consisting of circular discs (of $70 \pm 2 \mathrm{~mm}$ in diameter and $30 \pm 2 \mathrm{~mm}$ in thickness) were prepared by coring and cutting each concrete cube in accordance with the draft standard method for preparation of test specimens [1]. Five cores were taken from each panel. Three cores were used for OPI and sorptivity testing, and the other two cores were used for the chloride conductivity tests [1-4].

\section{Results and Discussion}

4.1. Compressive Strength Results. Three 28-day cubes of $100 \mathrm{~mm}$ size were tested for compressive strength, and the results were averaged for each mix. The average compressive strengths obtained have been plotted in the graph shown in Figure 1 (and also presented in Table 1). It can be seen that the three $\mathrm{w} / \mathrm{c}$ 's of $0.4,0.5$, and 0.65 gave concrete strength grades that can be categorized as:

(i) high-strength concrete: $0.4 \mathrm{w} / \mathrm{c}$ concrete, 60 to $90 \mathrm{MPa}$,

(ii) medium-strength concrete $: 0.5 \mathrm{w} / \mathrm{c}$ concrete, 40 to $60 \mathrm{MPa}$,

(iii) normal-strength concrete: $0.65 \mathrm{w} / \mathrm{c}$ concrete, 25 to $40 \mathrm{MPa}$.

Some mixes were cast at $\mathrm{w} / \mathrm{c}$ ratio of 0.5 , with or without filler sand (FS) to assess the influence of filler sand (see Table 1). The 28-day strength results (see Table 1) seemed to show a trend with higher results for mixes containing a combination of both filler sand and having higher extender contents, that is, for cement types CEM IV 32.5R and CEM $\mathrm{II} / \mathrm{A}-\mathrm{V} 52.5 \mathrm{~N}$. However, the increases in strengths were small 
TABLE 1: Mixtures for the various concretes.

\begin{tabular}{lcccc}
\hline & \multicolumn{2}{c}{ Cements: CEM I $42.5 \mathrm{~N}$, CEM II/A-V52.5N, CEM } & \multicolumn{2}{c}{ Cements: CEM I 42.5N FS, CEM II/A-V } \\
& \multicolumn{2}{c}{ IV/B-V 32.5R, CEM II/A-M (V-L) } & 52.5N FS \\
& w/c $=0.65$ & w/c $=0.5$ & w/c $=0.4$ & 7.7 \\
Cement (kg) & 6.4 & 7.6 & 3.5 & 0.5 \\
Water (kg) & 4.2 & 3.8 & 20.3 & 3.8 \\
19 mm dolomite stone (kg) & 20.3 & 20.3 & 16.0 & 20.3 \\
Dolomite crusher sand (kg) & 16.0 & 16.0 & 0 & 13 \\
Filler sand (kg) & 0 & 0 & 40 & 3.2 \\
Admixture Chryso 209 (mls) & 0 & 0 & &
\end{tabular}

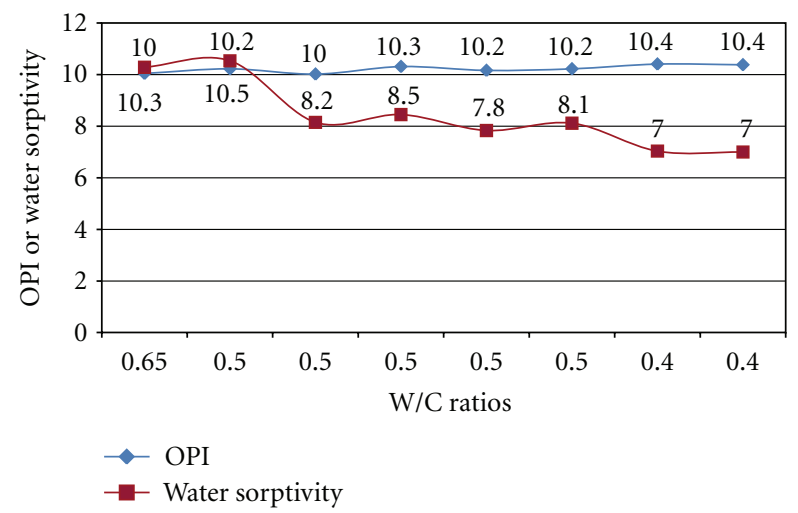

FIGURE 2: OPI and water sorptivity results for CEM I $42.5 \mathrm{~N}$ at different $\mathrm{w} / \mathrm{c}$ ratios.

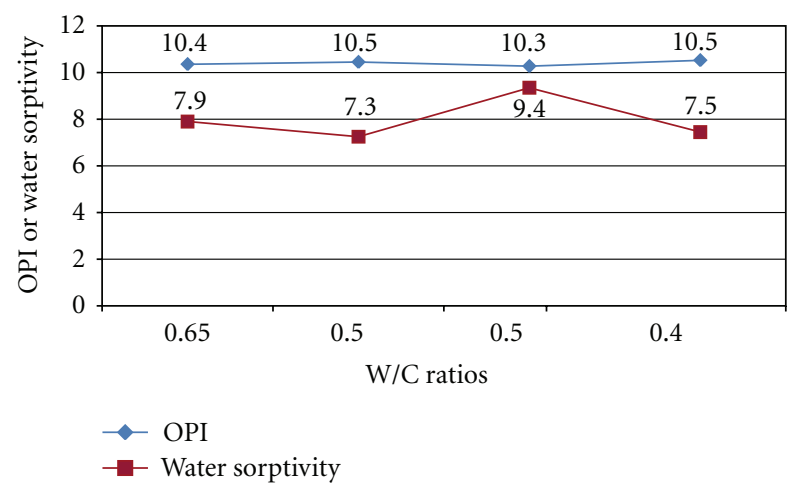

FIGURE 3: OPI and water sorptivity results for CEM II/A-V $52.5 \mathrm{~N}$ at different $\mathrm{w} / \mathrm{c}$ ratios.

and may be considered negligible. Mixes for cement types CEM I $42.5 \mathrm{~N}$ and CEM IV/B-V 32.5R made at $\mathrm{w} / \mathrm{c}$ ratios of 0.4 were consolidated by vibration and by hand compaction to evaluate possible effects of compaction on durability indices. Interestingly, hand compaction gave slightly higher 28 -day strength results compared to vibration (see Table 2).

4.2. Durability Test Results. As previously mentioned, the consortium of three South African index tests consisting of oxygen permeability, sorptivity, and chloride conductivity were used to assess the durability performance of the

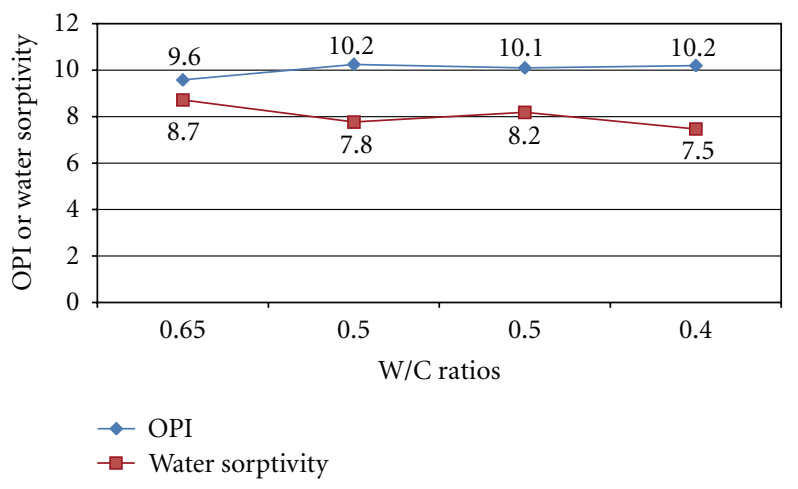

FIGURE 4: OPI and water sorptivity for CEM II/A-M (V-L) $42.5 \mathrm{~N}$ at different $\mathrm{w} / \mathrm{c}$ ratios.

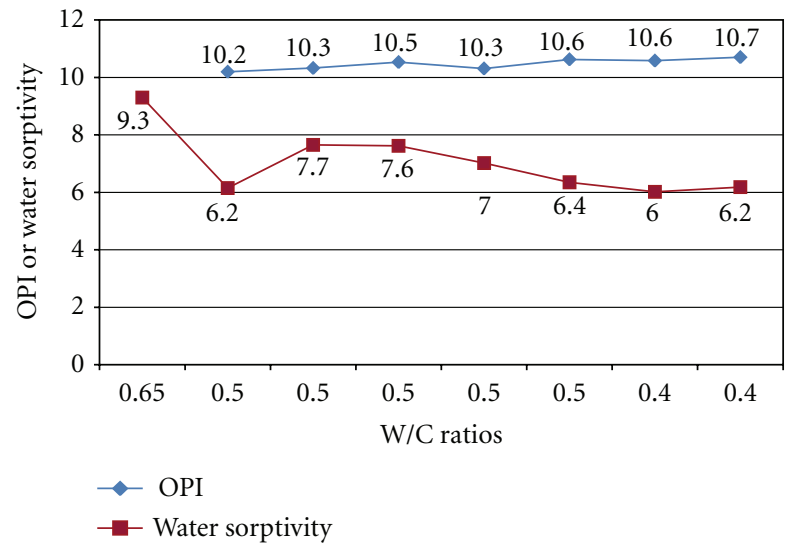

FIGURE 5: OPI and water sorptivity results for CEM IV/B-V 32.5R at different $\mathrm{w} / \mathrm{c}$ ratios.

concrete mixtures. Table 2 presents the results of all the durability tests conducted on the various concrete mixtures.

4.2.1. Oxygen Permeability and Water Sorptivity. The averaged results for oxygen permeability index (OPI) and water sorptivity (SORP) were plotted in different groupings. Firstly, each cement type was plotted at the three different w/c ratios of 0.65, 0.5, and 0.4 as shown in Figures 2, 3, 4, and 5. This was done in order to observe the trends as influenced by the cement type and w/c ratio. It can be seen that all the OPI results fall within the categories of good 
TABLE 2: The 28-day strengths, OPI, water sorptivity, and chloride conductivity results for different cement types and different w/c ratios.

\begin{tabular}{|c|c|c|c|c|c|}
\hline Cement type & W/C Ratio & $\begin{array}{l}\text { Average } 28 \text {-day } \\
\text { Strengths (MPa) }\end{array}$ & Average OPI & $\begin{array}{l}\text { Average sorptivity } \\
\left(\mathrm{mm} / \mathrm{hr}^{0.5}\right)\end{array}$ & $\begin{array}{c}\text { Average chloride } \\
\text { conductivity }(\mathrm{mS} / \mathrm{cm})\end{array}$ \\
\hline CEM I $42.5 \mathrm{~N}$ & 0.65 & 31.9 & 10.0 & 10.3 & 2.78 \\
\hline CEM I $42.5 \mathrm{~N}$ & 0.5 & 52.3 & 10.2 & 10.5 & 2.07 \\
\hline CEM I $42.5 \mathrm{~N}$ & 0.4 & 57.3 & 10.4 & 7.0 & 1.49 \\
\hline CEM I $42.5 \mathrm{~N}$ FS & 0.5 & 50.2 & 10.0 & 8.2 & \\
\hline CEM I $42.5 \mathrm{~N}$ FSH & 0.5 & 56.1 & 10.3 & 8.5 & \\
\hline CEM I $42.5 \mathrm{~N} \mathrm{H}$ & 0.4 & 68.6 & 10.7 & 6.2 & \\
\hline CEM I $42.5 \mathrm{~N}$ FSP & 0.5 & 55.2 & 10.2 & 7.8 & \\
\hline CEM I 42.5N FS Poker Panel & 0.5 & & 10.2 & 8.1 & \\
\hline CEM II/A-V 52.5N & 0.65 & 43.0 & 10.4 & 7.9 & 2.01 \\
\hline CEM II/A-V 52.5N & 0.5 & 58.1 & 10.5 & 7.3 & 1.90 \\
\hline CEM II/A-V 52.5N & 0.4 & 87.2 & 10.5 & 7.5 & 1.60 \\
\hline CEM II/A-V 52.5N FS & 0.5 & 66.2 & 10.3 & 9.4 & \\
\hline CEM IV/B-V 32.5R & 0.65 & 26.6 & & 9.3 & 2.32 \\
\hline CEM IV/B-V 32.5R & 0.5 & 42.3 & 10.2 & 6.2 & 1.57 \\
\hline CEM IV/B-V 32.5R & 0.4 & 66.2 & 10.6 & 6.0 & 1.26 \\
\hline CEM IV/B-V 32.5R FS & 0.5 & 46.8 & 10.3 & 7.7 & 1.73 \\
\hline CEM IV/B-V 32.5R FSH & 0.5 & 50.8 & & & 1.82 \\
\hline CEM IV/B-V 32.5R H & 0.4 & 67.6 & 10.7 & 6.2 & \\
\hline CEM IV/B-V 32.5R FSP & 0.5 & 49.9 & 10.3 & 7.0 & 1.72 \\
\hline $\begin{array}{l}\text { CEM IV/B-V 32.5R FS Poker } \\
\text { Panel }\end{array}$ & 0.5 & & 10.6 & 6.4 & \\
\hline CEM II/A-M (V-L) 42.5N & 0.65 & 33.8 & 9.6 & 8.7 & 2.34 \\
\hline CEM II/A-M (V-L) 42.5N & 0.5 & 61.5 & 10.0 & 7.8 & 1.81 \\
\hline CEM II/A-M (V-L) 42.5N & 0.4 & 73.2 & 10.2 & 7.5 & 1.61 \\
\hline CEM II/A-M (V-L) 42.5N FS & 0.5 & 59.3 & 10.1 & 8.2 & \\
\hline
\end{tabular}

FS: filler sand, FSH: filler sand after hand compaction, FSP: filler sand after poor compaction, done simply by lifting the filled concrete mould $20 \mathrm{~mm}$ off the floor and dropping it five (5) times.

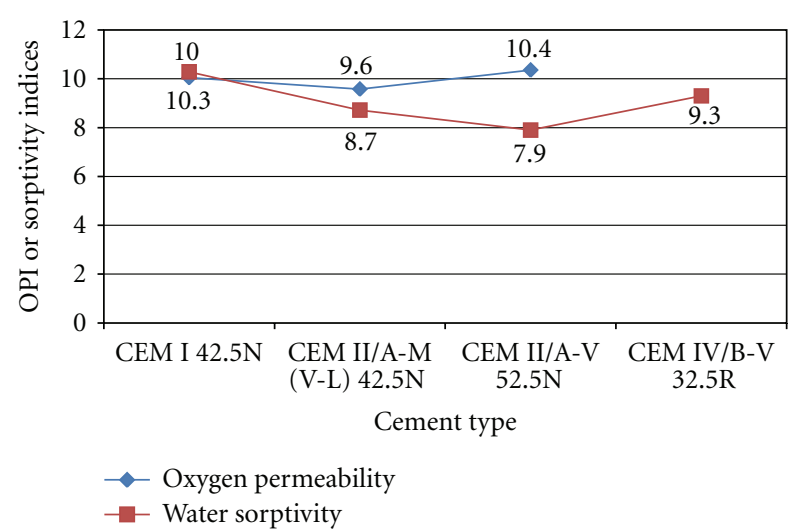

FIGURE 6: OPI and water sorptivity indices for different cement types at a w/c ratio of 0.65 .

$(\mathrm{OPI}>9.5)$ and excellent $(\mathrm{OPI}>10)$ as per the durability classification in [5]. There seems to be a trend showing that the oxygen permeability index increases as the w/c ratio decreases. However, this trend is not significant due to the closeness of results of the different w/c ratios, although for
CEM IV/B-V 32.5R the trend is quite distinct. It is interesting to note that although CEM II A-V 52.5N mix has the highest 28 -day strength of up to about $90 \mathrm{MPa}$, its OPI index is similar or slightly lower than that of CEM IV/B-V 32.5R for the same w/c ratio. In general, the oxygen permeability test results seem to be less sensitive to changes in w/c ratio than changes in cement type.

It is evident that as the water/cement ratio increases, the water sorptivity increases and this trend was quite distinct. It is interesting that the CEM IV/B-V 32.5R cement type gave the best sorptivity results, while all the higher-strength cements gave poorer results. At $0.65 \mathrm{w} / \mathrm{c}$ ratios, the plain ordinary Portland cement (CEM I 42.5N) mixes gave high water sorptivity values of SORP $=10.3 \mathrm{~mm} / \mathrm{hr}^{0.5}$, which fall under the poor durability class, as compared to the lower values for the cements containing extenders, namley, SORP $=7.9 \mathrm{~mm} / \mathrm{hr}^{0.5}$ for CEM II/A-V $52.5 \mathrm{~N}, 8.7 \mathrm{~mm} / \mathrm{hr}^{0.5}$ for CEM II/A-M (V-L) $42.5 \mathrm{~N}, 9.3 \mathrm{~mm} / \mathrm{hr}^{0.5}$ for CEM IV/B-V $32.5 \mathrm{R}$. These results suggest that the use of extenders leads to reduction in water sorptivity of the concrete. Also, Figures 2, 3,4 , and 5 show that the water sorptivity test is more sensitive to changes in cement type and water/cement ratios than the oxygen permeability test. The water sorptivity results were 


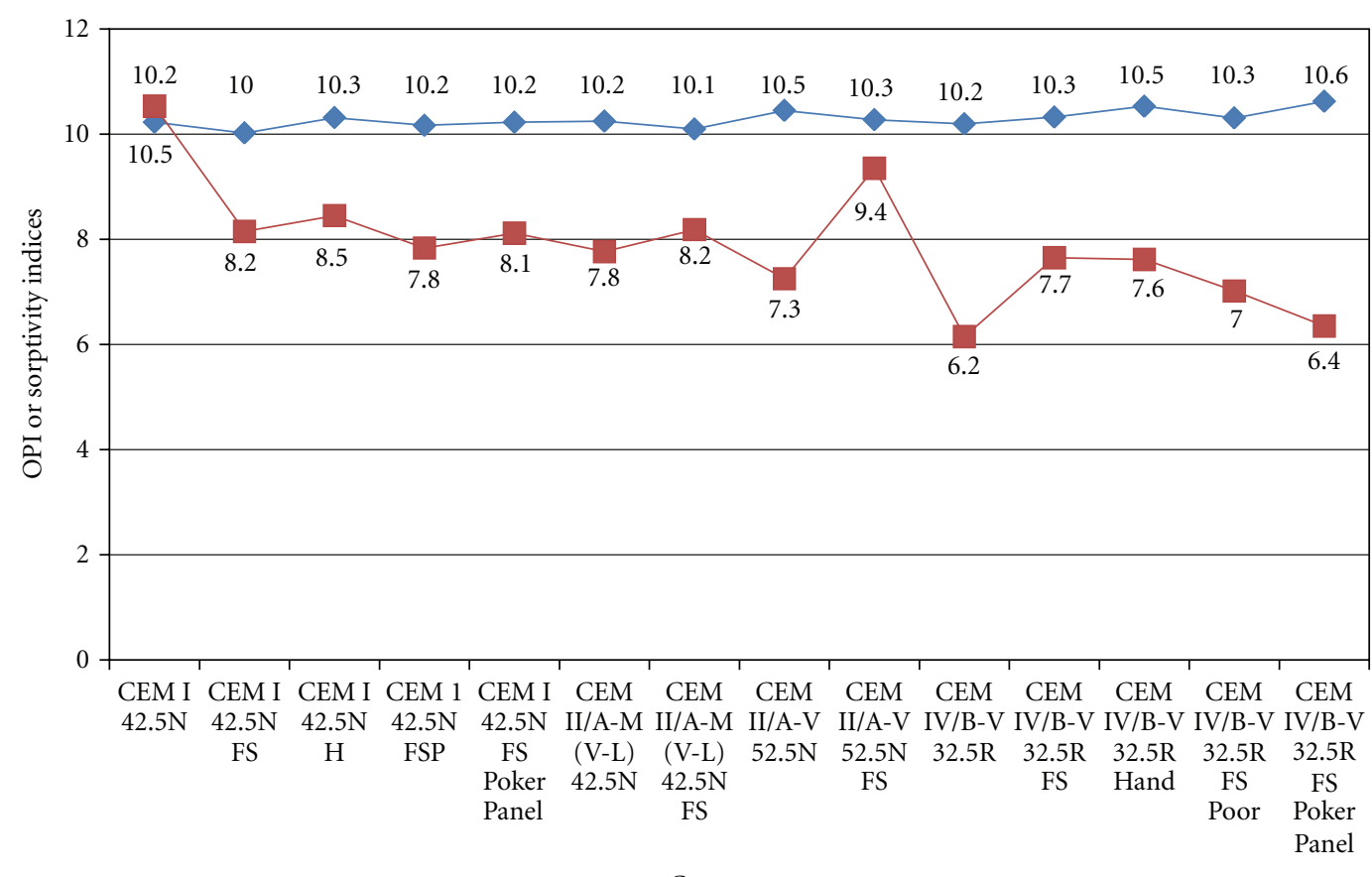

Cement type

- Oxygen permeability
- Water sorptivity

FIGURE 7: OPI and water sorptivity indices for different cement types at a w/c ratio of 0.5 .

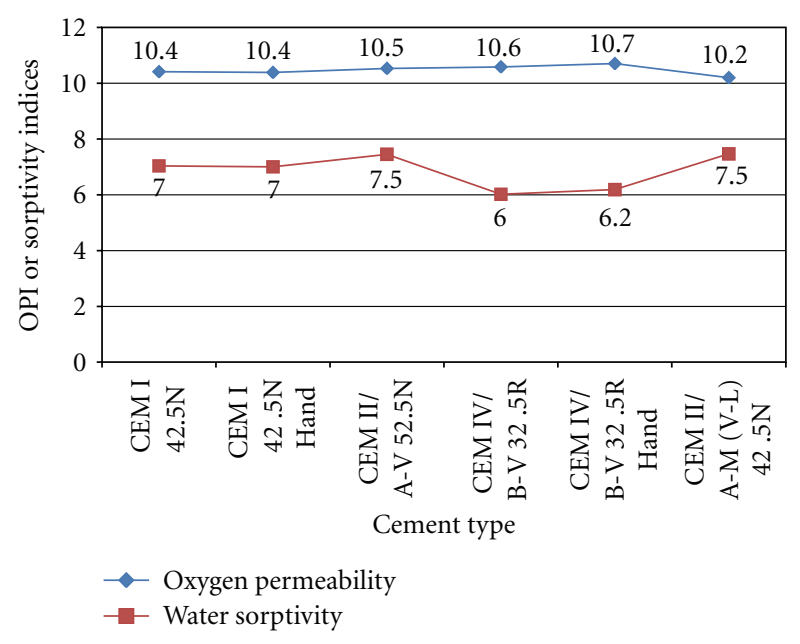

FIGURE 8: OPI and water sorptivity indices for different cement types at a $\mathrm{w} / \mathrm{c}$ ratio of 0.4 .

also more variable than the oxygen permeability index test results.

Figures 6, 7, and 8 give the trends for the OPI and water sorptivity results for each cement type at a given water/ cement ratio. Oxygen permeability results for the blended cement CEM II A-M (V-L) $42.5 \mathrm{~N}$ were better than those of CEM I $42.5 \mathrm{~N}$. The OPI results for CEM IV/B-V 32.5R mixes of $0.65 \mathrm{w} / \mathrm{c}$ were too variable and could not be included in the data. As previously noted, water sorptivity was definitely

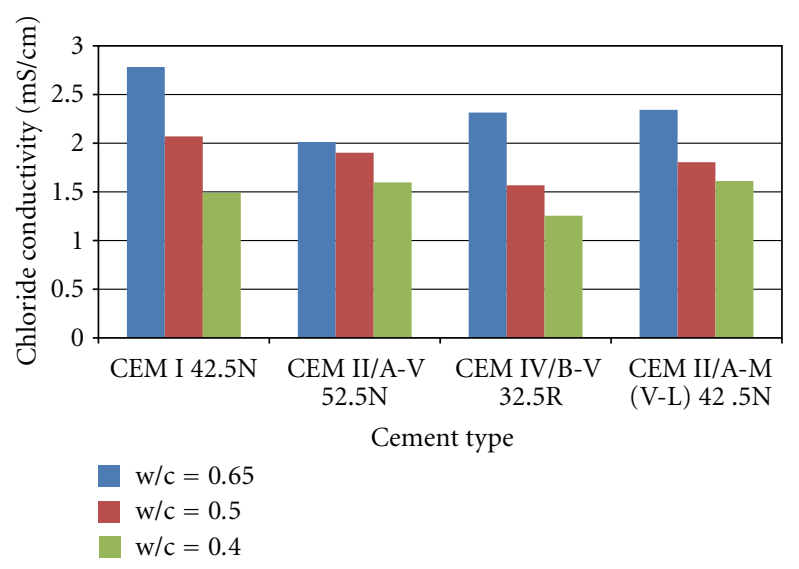

FIGURE 9: Chloride conductivity results for different cement types and concretes of normal, medium, and high strength.

reduced when using blended cement CEM II A-M (V-L) $42.5 \mathrm{~N}$ compared to CEM $142.5 \mathrm{~N}$ at $\mathrm{w} / \mathrm{c}=0.65$, which promotes the need to use blended cements in concrete. It can be clearly seen from Figures 6, 7, and 8 that while the performance for the normal and medium strength concretes of $0.65 \mathrm{w} / \mathrm{c}$ and $0.5 \mathrm{w} / \mathrm{c}$, respectively, is sensitive to the cement type used in the mixtures, all the concretes of $0.4 \mathrm{w} / \mathrm{c}$ made from the different cement types gave similar OPI values and similar sorptivity indices, indicating that the cement type has little or no significant influence on durability performance of HSC. 
4.2.2. Chloride Conductivity. Fifteen of the twenty-four mixes were tested for chloride conductivity (CLC). The tests included mixes for each cement type covering the three different w/c ratios as shown in Figure 9 (see also Table 2). The different mixes tested include CEM IV B-V 32.5R with concretes of the w/c ratio of 0.5 . This cement type generally showed the best durability performance for oxygen permeability and water sorptivity. As expected, the lower w/c ratio of 0.4 gave the lowest and best CLC results for all cement types, the best performing cement being CEM IV/B-V 32.5R. At $\mathrm{w} / \mathrm{c}$ ratio of $0.5, \mathrm{CEM}$ IV/B-V 32.5R had the lowest result, but at w/c ratio of 0.65 , CEM II/A-V $52.5 \mathrm{~N}$ had the lowest chloride conductivity result. CEM IV/B-V 32.5R and CEM I $42.5 \mathrm{~N}$ cements used in the $0.4 \mathrm{w} / \mathrm{c}$ concretes gave results falling in the good durability classification [4], while higher $\mathrm{w} / \mathrm{c}$ 's gave poorer chloride indices regardless of the cement type.

\section{Conclusions}

The following findings have been reached from the foregone investigation.

(1) High-strength concretes made from the different cement types gave similar OPI values and similar sorptivity indices with best durability performance being shown by the CEM IV 32.5R. For the normal and medium strengths, plain cement concretes gave higher sorptivity values compared to the cements containing extenders.

(2) With high-strength concretes, cement type has little or no significant influence on permeability and sorptivity. Consistent with these observations, the high-strength cement CEM II $52.5 \mathrm{~N}$ gave similar OPI results and similar sorptivity indices in all the mixes, while the cements of lower strength grades $42.5 \mathrm{~N}$ and $32.5 \mathrm{R}$ showed changes (improvement) in index results with decrease in $\mathrm{w} / \mathrm{c}$.

(3) The CLC indices of the concretes reduced with increase in strength, while the blended cements CEM IV/B$\mathrm{V}$ 32.5R and CEM II/A-V 52.5N gave better overall performance, suggesting that cement types play a significant role in CLC performance and that concrete strength alone has limited influence.

(4) The CLC indices of the concretes were generally poor with HSC giving values in the range of 1.3 to $1.6 \mathrm{mS} / \mathrm{cm}$, indicating that use of standard cements alone appears to be insufficient for high chloride resistance and may require incorporation of extenders in order to achieve superior performance.

\section{References}

[1] SABS, "Concrete durability index testing, in: part 1: preparation of test specimen," Tech. Rep. SANS 516-1, SABS Standards Division, Pretoria, South Africa, 2009.

[2] SABS, "Concrete durability index test, in: part 2: oxygen permeability test," Tech. Rep. SANS516-2, SABS Standards Division, Pretoria, South Africa, 2009.

[3] SABS, "Concrete durability index testing, in: part 3: water sorptivity test," Tech. Rep. SANS 516-3, SABS Standards Division, Pretoria, South Africa, 2009.
[4] SABS, "Concrete durability index testing, in: part 4: chloride conductivity and porosity tests," Tech. Rep. SANS 516-4, SABS Standards Division, Pretoria, South Africa, 2009.

[5] M. G. Alexander, J. R. Mackechne, and Y. Ballim, Guide to the Use of Durability Indexes for Achieving Durability in Concrete Structures, Research Monograph No.2, Departments of Civil Engineering Science, University of Cape Town and University of the Witwatersrand, Cape Town, South Africa, 1999.

[6] W. Meeks Kenneth and J. Carino Nicholas, "Curing of high performance concrete: report of the State of the Art," NISTIR 6295, Building and Fire Research Laboratory, National Institute of Science and Technology (NIST), 1999.

[7] Z. Li and Y. Zhang, High-Performance Concrete: Handbook of Structural Engineering, chapter 15, CRC Press, Boca Raton, Fla, USA, 2005.

[8] H. G. Russell, "ACI defines high-performance concrete," Concrete International, vol. 21, no. 2, pp. 56-57, 1999.

[9] P. Zia, M. L. Leming, and S. H. Ahmad, "High performance concrete-a State- of the-Art Report," Tech. Rep. SHRP-C/FR91-103, North Carolina State University, 1991.

[10] S. P. Shah and W. J. Weiss, "High strength concrete: strength, permeability, and cracking," in Proceedings of the PCI/FHWA International Symposium on High Performance Concrete, pp. 331-340, Orlando, Fla, USA, 2000.

[11] C. H. Goodspeed, S. Vanikar, and R. A. Cook, "Highperformance concrete defined for highway structures," Concrete International, vol. 18, no. 2, pp. 62-67, 1996.

[12] P. K. Mehta and P. J. M. Monterio, Concrete: Microstructure, Properties and Materials, McGraw-Hill, New York, NY, USA, 3rd edition, 2005.

[13] ACI 363, "State of the Art Report on high strength concrete," ACI 363, American Concrete Institute, 1997.

[14] ACI 441, "High strength concrete columns: state of the art report," Joint ACI-ASCE Committee 441, American Concrete Institute, 1996.

[15] B. J. Addis, High Performance Concrete, Portland Cement Institute, Midrand, South Africa.

[16] A. McFarlane, "High-strength concrete columns: a design guide," Structural Engineer, vol. 85, no. 6, pp. 31-38, 2007.

[17] J. Li and Y. Yao, "A study on creep and drying shrinkage of high performance concrete," Cement and Concrete Research, vol. 31, no. 8, pp. 1203-1206, 2001. 

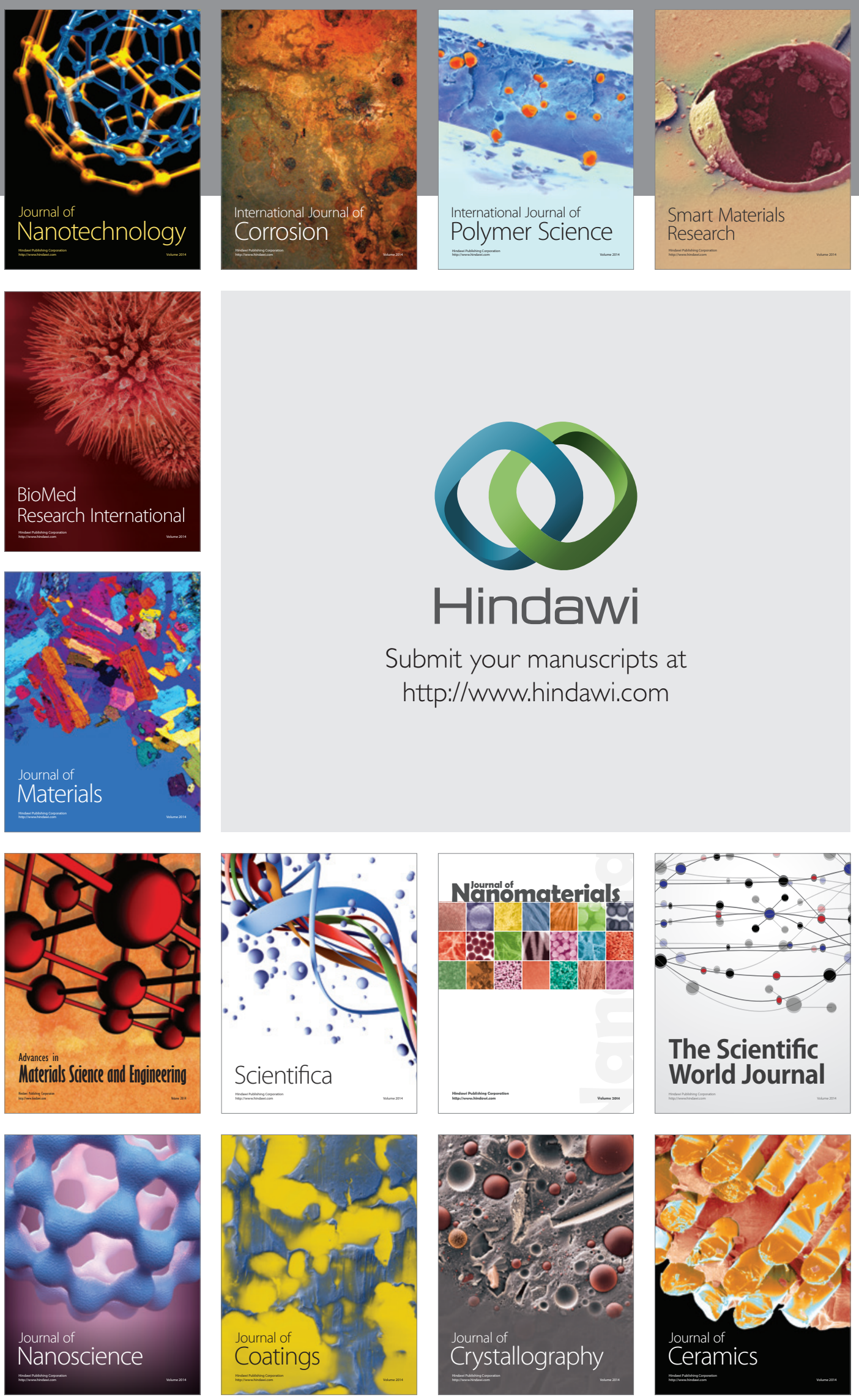

The Scientific World Journal

Submit your manuscripts at

http://www.hindawi.com

\section{World Journal}

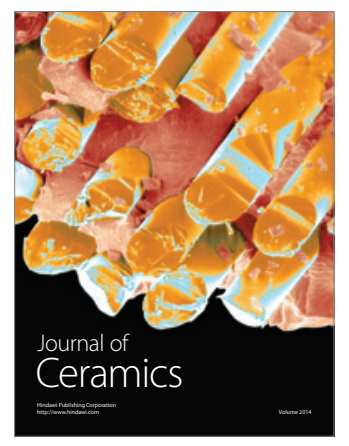

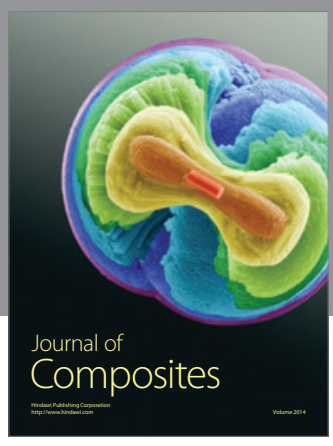
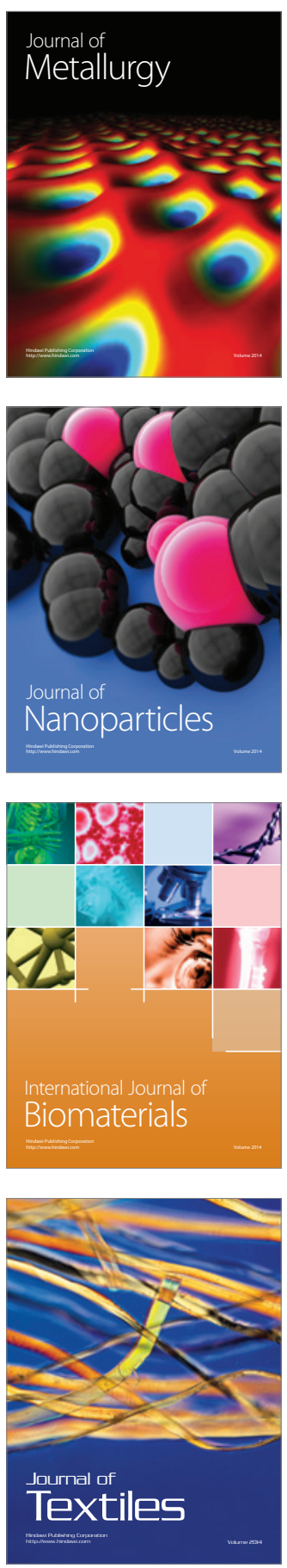